\title{
Evaluation of road pavement density using ground penetrating radar
}

\begin{abstract}
This study describes an analysis of Ground Penetrating Radar (GPR) measurements at frequency range of 1.7-2.6 GHz to get a relationship between attenuation and density for nine road pavements slabs with different densities. There are about four different frequencies had been tested. The method is simple, fast, non-destructive and accurate way to determine the density of road pavement. Density is a one of the important parameter in order to determine the compressive strength of road pavement for road user safety. In laboratory, the measurement system consists of a signal generator $(250 \mathrm{kHz}-3 \mathrm{GHz})$ as a source, spectrum analyzer $(100 \mathrm{~Hz}-8 \mathrm{GHz})$, directional coupler with adapter and horn antenna. The first part of the measurement system setup is to determine the amplitude of transmitted wave (received signal strength). A few of received signal strength and attenuation for nine road pavement slab samples were taken at four different frequencies. An instantaneous method for measuring the density of road pavement was developed by using microwave reflection technique and free space method. The MATLAB software is used to analyze the measurement data and also for the graphs comparisons. At the end of this study, it is found that density plays an important factor in causing a major in the recorded signal strength as well as the differences of attenuation of the GPR signal.
\end{abstract}

Keyword: Density, pavement slab, received signal strength, attenuation, road pavements 